\title{
Study on the treatments and countermeasures for liquefiable foundation
}

\author{
Binhua $\mathrm{Xu}^{1,2,3, *}$, Ning $\mathrm{He}^{1,2}$, and Denghua $\mathrm{Li}^{1,2}$ \\ ${ }^{1}$ Geotechnical Engineering Department, Nanjing Hydraulic Research Institute, Nanjing 210029, China \\ ${ }^{2}$ State Key Laboratory of Hydrology-Water Resources and Hydraulic Engineering, Nanjing 210029, \\ China \\ ${ }^{3}$ Hohai University, Nanjing 210098, China
}

\begin{abstract}
This paper summarizes the current treatments and countermeasures for liquefiable foundations, and divides the existing antiliquefaction countermeasures into two categories. One of the ideas is proceeding from the properties of liquefiable foundation soils, by the means of improvement for the soil's qualities to enhance the capacity of soil's anti-liquefaction in the early stage. The other idea is considering from the stress conditions of liquefiable foundation soils, and to reduce the liquefaction-induced disasters by changing the stress conditions of the soil. The advantages and disadvantages of various anti-liquefaction measures were analysed by verifying the effectiveness of field applications of antiliquefaction measures against ground liquefaction hazards, and the applicable conditions of various anti-liquefaction measures were classified. This paper provides experience for resisting soil liquefaction disasters.
\end{abstract}

\section{Introduction}

The earthquake is one of the most serious natural disasters. Large earthquakes often cause huge loss of human life and property. Since the earthquakes of Niigata in Japan and Alaska in the United States in 1964, the liquefaction of soil caused by earthquakes has gradually attracted the attention of scholars from various countries[1]. Liquefaction of soil is the behavior and process of the transformation of soil from solid to liquid due to the decrease of effective stress caused by the increase of excess pore water pressure. After the soil liquefaction occurs, the soil's effective stress decreases and followed by the decreasing or even losing of the soil's shear strength, and a large amount of liquefaction deformation of the foundation occurs. On the one hand, liquefaction will induce the settlement and deformation of overlying structure, and on the other hand, it will lead to the floatation of buried pipelines and storage tanks and other cavity structures. The settlement, deformation, and floatation have serious consequences for the engineering structure[2].

In order to ensure the normal use of engineering structures on liquefiable foundations and to meet safety requirements, the overall thinking has the following three aspects: (1) Changing the location of the project; (2) Changing the structure of the project; (3) Improve the foundation conditions. For most of the projects, ideas (1) and (2) are not feasible,

\footnotetext{
*Corresponding author: 317413076@qq.com
} 
because these two methods can't fundamentally solve the harm caused by soil liquefaction to humans. Therefore, we must proceed from the source of hazards by improving the foundation conditions to solve the problem of earthquake liquefaction fundamentally. By using some treatments and countermeasures to mitigate the risk of earthquake liquefaction and reduce the loss of life and property caused by earthquakes are the forces and targets of geotechnical workers, it requires the unremitting efforts of geotechnical workers.

On the basis of the mechanism of soil liquefaction, this study summarizes the treatment and protection measures of various liquefiable foundations in recent years firstly, and then analyzes the advantages and disadvantages of various anti-liquefaction measures by verifying the effectiveness of field applications of anti-liquefaction measures against ground liquefaction hazards, at last classifies the applicable conditions of various antiliquefaction measures. The purpose of this study is to provide experience for resisting soil liquefaction disasters.

\section{Mechanism of soil liquefaction}

The liquefiable foundation is a foundation mainly composed of slowly accumulated loose sand, furthermore it is almost a saturated foundation. The foundation composed of rock and clay with viscosity does not liquefy. Cao et al.[3] showed that earthquake liquefaction also occurs when gravelly soils meets certain conditions after they investigated Wenchuan earthquake. Saturated sand is a two-phase porous medium composed of soil particles and pore water. Under dynamic loading, saturated sand undergoes cyclic shearing and has a tendency of volume reduction. Volumetric deformation of saturated sand is constrained under undrained conditions. Therefore, this trend of volume reduction causes the increase of pore water pressure, a corresponding reduction of effective stress in the soil, which in turn leads to liquefaction. Based on the evolution law of liquefaction of cohesiveless soil, Wang[4] classified three different typical liquefaction phenomena as sand boiling, flow slide, and circulating fluidity and interpreted the liquefaction mechanism of three different typical liquefaction phenomena. Shi et al.[5] proposed that when the pore pressure ratio of sand is equal to 1, the strength of sand is almost equal to zero and the physical character of sand is similar to the liquid, this phenomenon can be called sand liquefaction. Wang et al.[6] pointed out that the liquefaction mechanism of sand can be explained from the mechanism of pore pressure increase. Chen[7] summed up that the liquefaction of saturated sand under earthquake must have two basic conditions at the same time: (1) The vibration intensity is enough to make the soil structure destroyed; (2) After the soil structure is destroyed, the vibration excess pore water pressure gradually increases with the increase of the number of stress cycles, furthermore the magnitude of excess pore water pressure is ultimately sufficient to make the shear strength of saturated sand partial or total disappear.

\section{Treatments and countermeasures of liquefaction}

According to the mechanism of earthquake liquefaction, it can be concluded that there are several key conditions for earthquake liquefaction in soil: (1) The foundation soil is coarsegrained soil (sandy or gravelly), that is, there is almost no cohesion between soil particles; (2) Foundation soil is in the state of loose, saturated, large pores and low density; (3) The foundation soil is in an undrained state. Treatment of liquefiable foundations should be considered from the above several key factors to prevent it from liquefaction.

From the above analysis of the conditions for the soil liquefaction, the anti-liquefaction countermeasures can be divided into the following two categories: One of the ideas is proceeding from the properties of liquefiable foundation soils, by the means of improvement for the soil's qualities to enhance the capacity of soil's anti-liquefaction in the 
early stage. For example: (1) Reducing the void ratio of liquefiable foundation soil and improving the compactness of the foundation; (2) Changing the structural properties of the liquefiable foundation soil, strengthening the structural connection between the soil particles and reducing the particle movement; (3) Reducing groundwater level and reducing the saturation of liquefiable soil. The other idea is considering from the stress conditions of liquefiable foundation soils, and to reduce the liquefaction-induced disasters by changing the stress conditions of the soil. For example: (1) Applying the non-liquefied layer on the liquefiable soil layer to increase the effective stress of the liquefiable soil layer and improves the liquefaction resistance of the soil layer. (2) Constraining the deformation of soil to reduce the excess pore water pressure due to volume contraction, and changing the stress conditions of the soil under dynamic loading; (3) Changing the drainage conditions of the liquefiable foundation soil so that the excess pore water pressure is quickly dissipated. The following will summarize the treatments and countermeasures of liquefiable foundation in recent years, and compare the advantages, disadvantages and applicable conditions of various measures.

\subsection{Improvement for soil's qualities}

\subsubsection{Compaction method}

Compaction method is the most fundamental method of liquefaction mitigation. Otherwise called densification of liquefaction-prone sand. By reducing the void ratio of the liquefiable foundation soil, the compaction degree can be increased to reduce the liquefaction potential of the foundation. Since dense sand does not develop high excess pore water pressure as loose sand does and since dense sand does not deform so easily as loose sand, densification by means of vibration has been carried out widely. Adalier et al.[8] studied the reinforcement of the liquefiable foundation under the dam by the compaction method, and confirmed that the dense overburden layer can play an anti-liquefaction effect and reduce the settlement caused by the earthquake. However, the thickness of the compacted layer is not as thick as possible. There is an optimal viscous thickness. The common compact methods include dynamic compaction method, vibration compaction method, and blasting vibration compaction method.

\subsubsection{Method of changing the structural properties of soil}

According to the mechanism of earthquake liquefaction, under the action of cyclic dynamic load, the weak bonding of liquefiable soil makes the soil particles easily dislocation. This misalignment can cause the volume shrinkage of the soil skeleton, leading to the pore water pressure increase and the effective stress decrease. Furthermore, the shear resistance of the foundation soil will decrease. Therefore, by changing the structural properties of the liquefiable soil to enhance the connection between soil particles on the one hand can reduce the movement of soil particles to reduce the liquefaction potential, on the other hand can also increase the shear strength of soil.

Permeation grouting method(Fig. 1), deep mixing method and jet grouting method are common anti-liquefaction methods by changing the structural properties of the liquefiable soil in engineering. These methods develop cohesion in sandy soils and prevent large shear strain. Hence, excess pore water pressure does not rise. Permeation grouting is a method of injecting the silicon-based cement slurry or cohesive soil into liquefiable soil layer by way of infiltration. Deep mixing is a method of mixing soil with a cement-like material either by mechanical mixing. Jet grouting is a method of injecting cement-like material into liquefiable soil layer through high pressure. The role of silica-based cement grouts in the 
treatment of foundation soils was initially used to change the permeability of soils. The study of this method in seismic liquefaction started after the mid-1990s. Hayashi et al.[9-10] conducted in-house and field tests and found that when this silicon-based cement slurry was injected into the sand, the ability of the soil to resist liquefaction significantly increased. The grouted sand has an unconfined compression strength of, typically, $q_{u}=300-500 \mathrm{kPa}$. Rasouli et al.[11-12] grouted the liquefiable foundation of the runway of Fukuoka International Airport through a newly developed controlled-bending drilling rig to permeate the liquefaction foundation, to achieve controlled osmotic grouting under the runway and to eliminate other operational disturbances(Fig. 2).

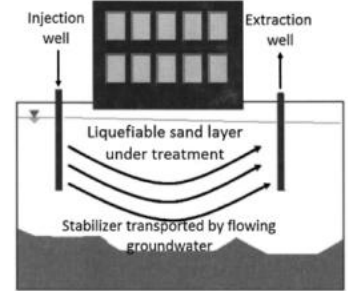

Fig. 1. Schematic of permeation grouting method[11].

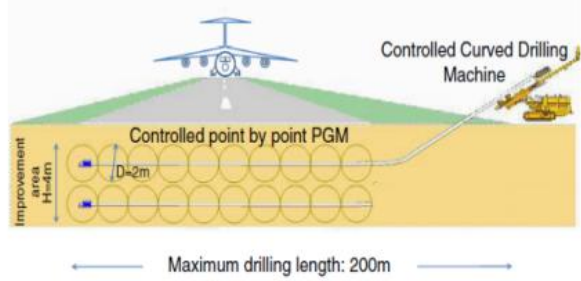

Fig. 2. Schematic of controlled permeation grouting method[11].

\subsubsection{Desaturation method}

When sand is not saturated with water, it is unlikely to liquefy. This is because the volume of unsaturated sand can change by compressing the volume of pore gas when dilatancy occurs. Therefore, the effective stress does not decrease significantly and the liquefaction potential is very low in soil lying above the ground water table. Studies have shown that when the saturation of sand is reduced from $100 \%$ to $70 \%$, the liquefaction resistance of sand changes significantly. As the saturation decreases, the resistance to liquefaction gradually increases and can exceed 3 times the fully saturated sample[13-16]. Similar conclusions have also gained support from more and more experimental results, and they began to propose engineering measures to reduce the saturation of sandy foundations(Fig 3). The commonly used desaturation methods include the dewatering method, air injection method[17-18], biogas method[19-20], chemical bubble method[21-22] and electrolysis method[23].

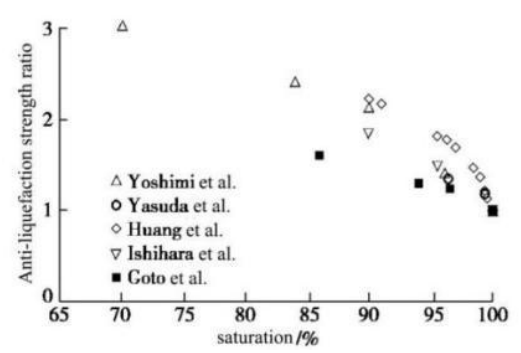

Fig. 3. Relation between liquefaction strength ratio and saturation.

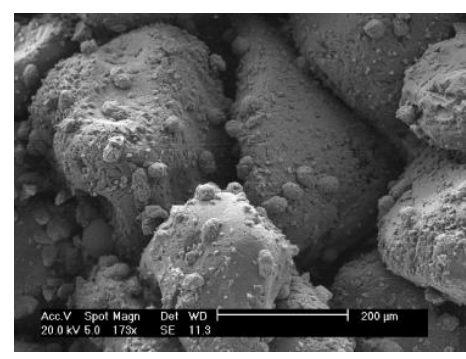

Fig. 4. Microstructural map after MICP treatment[34]

The dewatering method is the simplest common method of desaturation, this method remove the water by using deep wells. But this method will produce settlement. So it needs to control the differential settlement of existing buildings. The air injection method involves injecting air into the sand (or injecting it into the foundation through compacted sand piles) through an air-filled pump, and draining water close to the injection point to form an effective area for reducing satiety. However, the distribution of air bubbles in the 
air injection method is not uniform, which usually leads to poor desaturation effect. The biogas method is a method for producing nitrogen gas through the denitrification of microorganisms. The chemical bubble method generates gas by producing a chemical reaction in the sand by chemical substances. Although the bubble distributions by the chemical bubble method and the biological bubble method are more uniform than the air injection method, but they may cause environmental pollution problems. The electrolysis method produces gas by electrolyzing water and produces gas in saturated sand, which achieves saturation reduction. However, the electrical characteristics of the foundation are not clear. Based on the above constraints, the desaturation method has not been widely used in engineering.

\subsection{Changing the stress conditions of soil}

\subsubsection{Supercharging method}

Supercharging method is a commonly used anti-liquefaction foundation treatment method to change the stress state of soil. The non-liquefied weight gain layer is covered on the liquefiable soil layer by pressurization to increase the effective stress of the liquefiable soil layer and improve the anti-liquefaction ability of soil.

Juang et al.[24]analyzed the liquefaction of soil at 22 different locations in the area where the Chichi earthquake occurred in Taiwan through on-site SPT tests and indoor tests. The results show that there are thicker sections in the upper part. At the site of the clay coating, even if the liquefaction layer is found in the lower part, liquefaction failures such as surface subsidence and sand boiling are unlikely to occur, indicating that the effect of overburden pressure can increase the liquefaction resistance of the liquefiable soil layer. Common supercharging methods include the preloading method and overload methods.

\subsubsection{Constrained soil deformation method}

The constrained soil deformation method is an anti-liquefaction method that indirectly changes the stress state of soil under dynamic load, thereby reducing the damage caused by liquefaction, such as the reinforcement method and the underground continuous wall method[25]. There are two reasons why reinforcement method can improve the liquefaction resistance of the liquefiable foundation. The main reason is that due to the contact friction between the reinforced material and the foundation, the lateral tensile strength is enhanced, the stress and deformation state of the shallow soil are changed, and the shear strength of soil is improved. On the other hand, due to the deformation of the foundation, there will generate a lifting force on the middle of the foundation caused by the reinforced material, which makes the stress distribution of the foundation tends to be uniform, and reduces the stress concentration near the foundation, so that no stress concentration zone is formed under the foundation. It helps to prevent the unfolding of the plastic zone and limits the uneven settlement of the foundation soil. The underground continuous wall method mainly reduces the dislocation between soil particles under dynamic load through lateral restraints, thereby reducing the generated excess pore water pressure and changing the loss of soil effective stress to achieve anti-liquefaction effect.

\subsubsection{Promotion of the excess pore pressure dissipation method}

The promotion of the excess pore pressure dissipation method is an anti-liquefaction method that increases the effective stress by promote the excess pore pressure dissipation 
after dynamic load. The most common method of promoting pore water pressure dissipation is the gravel pile method[26] and sand compaction pile method[27]. The gravel pile and the sand compaction pile can effectively dissipate the super pore pressure accumulated in the soil around the pile due to the liquefaction of the soil. These two types of soil anti-liquefaction treatment pile method have been fully affirmed. At the same time sand compaction pile method is also a kind of compaction method.

In recent years, some scholars have developed some new anti-liquefaction methods that promote pore pressure dissipation. Tanaka et al.[28] used special steel sheet piles with drainage performance in the liquefiable soil layer for existing embankments and other underground structures for enclosing. Liu et al.[29] invented an anti-liquefaction and drainage rigid pile, by setting a groove on the side of a rigid pile, placing different engineering materials according to the type of groove to form a drainage channel, so that it has similar drainage effect as a gravel pile, and also has load bearing capacity like rigid pile. It can dissipate the excess pore water pressure generated in the foundation under earthquake action to achieve the effect of anti-liquefaction. Studies by Rasouli et al.[30] showed that although drainage piles can't significantly reduce the structural settlement caused by earthquakes, they play an important role in the prevention of liquefaction within a shallow depth of ground.

\section{Field application}

Based on the current situation of various anti-liquefaction measures in the field, the application effects, advantages and disadvantages of various anti-liquefaction measures are analyzed.

In several major earthquakes in the past 30 years, compaction method is the most widely used anti-liquefaction measure. The dynamic compaction method is suitable for anti-liquefaction treatment of large-area sites, and its effective treatment depth is about $10 \mathrm{~m}$ in field applications. However, the compaction method has the following disadvantages: (1) The noise produced by the compact method is relatively large, and it has a certain influence on surrounding buildings, which is not suitable for construction in the center of the city. (2) The compaction method has good application effects in sand foundations with good grading, but it is not effective in some foundations with poor gradation and high fines content.

Permeation grouting method, deep mixing method and jet grouting method fundamentally eliminate the source of "water" that causes the soil to liquefy by solidifying the soil. This method can not only avoid the liquefaction of sand, but also can greatly increase the bearing capacity of the foundation, and its effective treatment depth is also deeper, usually up to more than $20 \mathrm{~m}$. The disadvantage is that the cost of foundation treatment is high and it will cause soil pollution. In addition, with technological innovations in recent years, it is now possible to perform post-grouting treatment on existing unconsolidated construction sites through horizontal drilling equipment, this method can reinforce existing building sites without affecting its operation.

In the field of anti-liquefaction measures applied in Japan, there are related applications in Japan that reduce the groundwater level by pumping water and the physical gas injection method. Most of the Japanese desaturation methods are used in combination with the compaction sand pile method or preloading method. The anti-liquefaction effect is good, but it will cause uneven settlement in the existing buildings due to the reduction of the groundwater level, and the continuous pumping and injecting gas will cause massive use of human and material resources, resulting in higher costs. Other desaturation methods such as biogas method, chemical bubble method and electrolysis method are currently in the experimental stage, and the effectiveness of on-site resistance to earthquake liquefaction needs to be verified. 
In the cases of anti-liquefaction treatment in the Kushiro-Oki earthquake, the Hokkaido Toho Oki earthquake, the Hyogoken-Nanbu earthquake, and the East Japan Earthquake in Japan, many sites used sand compaction pile method alone or combined with sand compaction pile method[31]. The on-site treatment results have shown that the use of compaction sand piles for site resistance to liquefaction is reliable. The sand compaction pile technique is mature and its effect is good. The treatment depth is generally up to $10-20$ m.

The sand well method and the gravel pile method are almost exclusively used in Japan as the anti - liquefaction treatment of foundation. The main problem with this type of method is the presence of fine-grained migration in the soil, which blocks drainage channels and does not meet the expected drainage effect, affecting the liquefaction resistance of foundation. In Japan, the drainage method is mostly used together with the compaction sand pile method or the pre-press method as the on-site anti-liquefaction treatment measures.

In recent years, the microbial reinforcement method has attracted the attention of many scholars, such as the microbially-induced carbonate precipitation (MICP) technique. As a new method of microbial reinforcement, the qualities of soil can be improved and modified. It has been well applied in sealing leakage prevention and cementation reinforcement projects[32]. The unconfined compressive strength of sand after the improvement of microbial grouting can be increased to $20 \mathrm{MPa}$, and the calcium carbonate content can be as high as $27 \%[33]$. According to Cheng et al.'s study on the microstructure of sand after MICP treatment, as shown in Fig. 4, the structural properties of the treated sand changed significantly, and cementation between sand particles was evident[34]. Although this method has not been applied to the study of anti-liquefaction, the cementation effect produced by it can theoretically reduce the liquefaction potential of soil, and it needs to be verified by relevant experiments. In addition, relevant researches have been conducted to use microorganisms to generate gas to reduce soil saturation and thus reduce the liquefaction potential of soil. Therefore, the use of microbial reinforcement technology to treat liquefiable foundations is a future research trend.

\section{Conclusion}

The following methods are used in the mitigation of liquefaction-induced damage: (1) Based on the properties of the liquefiable foundation soil itself, the liquefaction resistance of the soil is enhanced by improving the soil properties; (2) Reducing liquefaction disasters by changing the stress conditions of soil. Ground anti-liquefaction measures should be screened according to site conditions, economic conditions and the surrounding environment. It is necessary to meet the requirements of anti-liquefaction treatment of the foundation and meet the requirements of economic factors and site construction conditions.

There are certain disadvantages to a single treatment method, so the combined effects of using multiple methods at the same site are better, and the combination form and application conditions of related anti-liquefaction measures need to be further studied. The treatment and protection of liquefiable foundations is a long-term research, reflecting the wisdom of humans adapting to nature. At the same time, through the effective treatment of liquefiable foundations, the wartime safety of coastal buildings and components can be ensured.

\section{Acknowledgements}

This work was financially supported by the National Key Research and Development Plan of China (2017YFC0405005, Research on Key Technologies and Equipment for 
Emergency Rescue and Quick Repair of South-to-North Water Transfer Project), National Natural Science Foundation of China (51579152).

\section{References}

1. Liu H L, Yu X J. Advance in Soil Dynamics and Geotechnical Earthquake Engineering[J]. Journal of Hohai University (Natural Sciences), 1999(1): 6-15.

2. Chen Y M, Gao X, Liu H L. Simplified method of flow deformation induced by liquefied sand[J]. Rock and Soil Mechanics, 2013, 36(6): 1567-1573.

3. Cao Z Z, Liu Y D, Yuan X M. Liquefaction characteristics and mechanism of gravelly soils[J]. Chinese Journal of Geotechnical Engineering, 2016, 38(7): 1165-1174.

4. Wang W S. The dynamic strength and liquefaction characteristics of soil[M]. Beijing:China Electric Power Press, 1997.

5. Shi Z J, Wang L M. Soil dynamic characteristics-Liquefaction potential and hazard assessment[M]. Beijing: Seismological Press, 1999.

6. Wang G, Zhang J M. Recent advances in seismic liquefaction research[J]. Advances in Mechanics, 2007, 37(11): 575-589.

7. Chen G X. Earthquake engineering[M]. Beijing:Science Press, 2007.

8. Adalier K, Sharp M K. Embankment dam on liquefiable foundation - Dynamic behavior and densification remediation[J]. Journal of Geotechnical and Geoenvironmental Engineering, 2004,130(11): 1214-1224.

9. Hayashi K, Miyoshi T, Yoneya H, et al. Fundamental tests on stabilized sand using acid silica sol[C]//2nd Int. Conf. on Ground Improvement Geosystems. Canada: International Association for Earthquake Engineering, 1996: 695-700.

10. Hayashi K, Yoshikawa R, Hayashi N, et al. A field test on a new chemical grouting method to improve the liquefaction resistance of sandy layers beneath the existing structures[C]// International Symposium on Coastal Geotechnical Engineering in Practice. Yokohama, 2000: 291-297.

11. Rasouli R, Hayashi K, Zen K, et al. Controlled permeation grouting method for mitigation of liquefaction[J]. Journal of Geotechnical and Geoenvironmental Engineering, 2016, 142(11): 4016052.

12. Takano S, Hayashi K, Zen K, et al. Controlled Curved Drilling Technique in the Permeation Grouting Method for Improvement Works of an Airport in Operation[J]. Procedia Engineering, 2016, 143: 539-547.

13. Yoshimi Y, Tanaka K, Tokimatsu K. Liquefaction resistance of partially saturated sand[J]. Soils and Foundations, 1989, 29(3): 157-162.

14. Yasuda S, Kobayashi T, Fukushima Y. Effect of degree of saturation on the liquefaction strength of Masa[C]//Proceedings of 34th Japanese National Conference Geotechnical Engineering. Tokyo, 1999: 2071-2072.

15. Huang $\mathrm{Y}$, Tsuchiya $\mathrm{H}$, Ishihara $\mathrm{K}$. Estimation of partial saturation effect on liquefaction resistance of sand using P-wave velocity[C]// Proceedings of Japanese Geotechnical Society. Nerada: 1999: 431-434.

16. Ishihara $\mathrm{K}$, Tsuchiya $\mathrm{H}$, Huang $\mathrm{Y}$. Recent studies on liquefaction studied on sandeffect of saturation[C]/Proceedings of 4th International Conference on Recent Advance in Geotechnical Earthquake Engineering and Soil Dynamics. San Diego, 2001: 1-7. 
17. Okamura M, Ishihara M, Tamura K. Degree of saturation and liquefaction resistances of sand improved with sand compaction pile[J]. Journal of Geotechnical and Geoenvironmental Engineering, American Society of Civil Engineers, 2006, 132(2): 258-264.

18. Okamura M, Takebayashi M, Nishida K, et al. In-situ desaturation test by air injection and its evaluation through field monitoring and multiphase flow simulation[J].Journal of Geotechnical and Geoenvironmental Engineering, 2011, 137: 643-652.

19. He J, Ivanov V, Chu J. Mitigation of liquefaction of saturated sand using biogas[J]. Géotechnique, 2013, 63(4):267-275.

20. He J, Chu J. Undrained responses of microbially desaturated sand under monotonic loading[J]. Journal of Geotechnical and Geoenvironmental Engineering, 2014(12): 1-8.

21. Eseller-Bayat E, Yegian M K, Alshawabkeh A, et al. Liquefaction response of partially saturated sands (I): Experimental results[J]. Journal of Geotechnical and Geoenviromental Engineering, 2012, 139(7): 863-871.

22. Eseller-Bayat E, Yegian M K, Alshawabkeh A, et al. Liquefaction response of partially saturated sands (II): empirical model[J]. Journal of Geotechnical and Geoenvironmental Engineering, 2012, 139(6): 872-879.

23. Yegian M K, Eseller-Bayat E, Alshawabkeh A, et al. Induced-partial saturation for liquefaction mitigation: experimental investigation[J]. Journal of Geotechnical and Geoenvironmental Engineering, 2007, 133(4): 372-380.

24. Juang $\mathrm{C} H$,Yang $\mathrm{S} \mathrm{H}, Y$ uan $\mathrm{H}$ M,et al. Liquefaction in the Chi-chi earthquake-effect of fines and capping non-liquefiable layers[J]. Soils and Foundations, 2005, 45(6): 89101.

25. Murugesan S,Rajagopal K. Geosynthetic-encased stone columns: Numerical evaluation[J]. Geotextiles and Geomembranes, 2006, 24(6): 349-358.

26. Park Y H, Kim S R, Kim S H, et al. Liquefaction ofembankments on sandy soils and the optimumcounter measure against the liquefaction[C]// 12th World Conference on Earthquake Engineering. Auckland, New Zealand, 2000(1): 1-5.

27. Tsukamoto $\mathrm{Y}$, Ishihara $\mathrm{K}$, Yamamoto $\mathrm{M}$, et al. Soil densification due to static sand pile installation for liquefaction remediation[J]. Soils and Foundations, 2000, 40(2): 9-20.

28. Tanaka H, Kita H, Iida $\mathrm{T}$, et al. Liquefaction countermeasure using steel sheet pile with drain capability[J]. The Sumitomo Search, 1996(58): 72-81.

29. Liu H. Technological innovation methods and practices in geotechnical engineering[J]. Chinese Journal of Geotechnical Engineering, 2013, 35(1): 34 - 58.

30. Rasouli1 R, Towhata I, Akima T.Experimental Evaluation of Drainage Pipes as a Mitigation against Liquefaction-Induced Settlement of Structures[J]. Journal of Geotechnical and Geoenvironmental Engineering, 2016, 142(9): 04016041.

31. Chen G X, Gu X F, Chang X D, et al. Review and implication of successful ground improvement cases about mitigating soil liquefaction induced by 8 strong earthquakes from 1989 to 2011[J]. Rock and Soil Mechanics, 2015, 36(4): 1102-1118.

32. Zhang Y L, Yang P. Research progress in microorganism improving soil properties[J]. Microbiology China, 2014, 41(10): 2122-2127.

33. Paassen L. Biogrout ground improvement by microbially induced carbonate precipitation[D]. Delft University of Technology, 2009.

34. Cheng L, Shahin M A, Cord-Ruwisch R. Bio-cementation of sandy soil using microbially induced carbonateprecipitation for marine environments [J]. Géotechnique, 2014, 64(12): 1010-1013. 